\title{
Some Empirical Observations on the Forward Exchange Rate Anomaly
}

\author{
Derek Bond, ${ }^{1}$ Michael J. Harrison, ${ }^{2}$ \\ Niall Hession, ${ }^{1}$ and Edward J. O'Brien ${ }^{2,3}$ \\ 1 University of Ulster, 2 Trinity College Dublin, and 3 CBFSAI
}

January 11, 2006

\begin{abstract}
This paper looks at issues surrounding the testing of fractional integration and nonlinearity in relation to the forward exchange rate anomaly of Fama (1984). Recent tests for fractional integration and nonlinearity are discussed and used to investigate the behaviour of three exchange rates and premiums. The findings provide some support for $I(1)$ exchange rates but suggest fractionality for premiums, mixed evidence on cointegration, and a strong possibility of time-wise nonlinearity. Significantly, when the nonlinearity is modelled using a random field regression, the forward anomaly disappears.
\end{abstract}

JEL Classification: C22, F31, F41

Keywords: Forward exchange rate anomaly, fractional Dickey-Fuller test, random field regression, nonlinearity.

\section{Introduction}

A substantial literature exists on the forward exchange rate anomaly and the risk premium. The basic anomaly is that the results of empirical studies suggest that foreign exchange markets are so inefficient at catching the future movements of exchange rates that they systematically predict these movements in the wrong direction. The seminal paper is that by Fama (1984); the classic surveys of the area are those of Hodrick (1987) and Engel (1996).

In recent years, two interrelated topics, which may have considerable relevance to the investigation of the forward anomaly, have attracted much attention. The first, deriving mainly from economic theory, is the possibility of nonlinearity in economic and financial relationships and its investigation using variations of the smoothed transition dynamic regression model of Granger and Teräsvirta (1993); see, for example, Sarno, Valente and Hyginus (2004), Baillie 
and Kiliç (2005), and Sarno (2005). The second, based mainly on econometric theory, is the role of time-series dynamics and, in particular, the possibility of fractional integration in explaining the anomaly; see Baillie and Bollerslev (2000), and Maynard and Phillips (2001).

These developments mirror in several ways the developments in econometric theory dealing with nonstationarity and nonlinearity of time series processes. It has been well known for many years that it is difficult to distinguish statistically between difference stationary series and nonlinear but stationary series; see, for example, Perron (1989), and Harrison and Bond (1992). A series of recent papers has considered the effects of nonlinearity on unit root tests such as the augmented Dickey-Fuller test; see Diebold and Inoue (2001), and Perron and $\mathrm{Qu}$ (2004). Others have examined the reverse scenario: the effect of nonstationarity on tests for nonlinearity; see Hsu (2001), and Krämmer and Sibbertsen (2002). However, recent work by Gil-Alana (2004), Dolado, Gonzalo and Mayoral (2005), and Mayoral (2005) has tested explicitly for difference stationarity and nonlinearity. In most of these tests, the form of the nonlinearity needs to be known.

The aim of this paper is to use two recent developments in econometric theory to explore the forward exchange rate anomaly. The first of these is the Dolado, et al. (2002) fractional augmented Dickey-Fuller (FADF) test, and the second is the Hamilton (2001) method of random field regression for investigating nonlinearity. In Section 2, the background to the forward rate anomaly and the notation used in the paper are briefly explained, while in Section 3 some of the attempts at explaining the anomaly are described. In sections 4 and 5 , respectively, the Dolado, et al. FADF test and the Hamilton random field model are outlined. Section 6 describes the details of the methodology used, and in Section 7 the results of an application to the cross exchange rates for sterling and the Australian dollar, sterling and the Canadian dollar, and sterling and the Japanese yen are presented and discussed. Finally, Section 8 offers a brief summary and conclusion, which considers how the results reported relate to the general discussion of the forward exchange rate anomaly.

\section{The anomaly}

The forward rate anomaly has played a central role in the theory of foreign exchange market efficiency. Consider, as a starting point, the covered interest rate parity (CIP) hypothesis of international macroeconomics, which states that

$$
f_{t, k}-s_{t}=i_{t, k}-i_{t, k}^{*},
$$

where $s_{t}$ and $f_{t, k}$ are the $(\log )$ spot and forward rate at time $t, k$ is the length of the forward contract, and $i_{t, k}$ and $i_{t, k}^{*}$ are the $k$ periods to maturity nominal interest rates available on similar domestic and foreign assets, respectively. The validity of CIP is generally accepted; see Sarno and Taylor (2003, Chapter 2) for a survey of evidence. 
Closely linked to the CIP hypothesis is the uncovered interest rate parity (UIP) condition that can be seen as a central parity condition for foreign exchange market efficiency:

$$
E_{t}\left(s_{t+k}-s_{t}\right)=i_{t, k}-i_{t, k}^{*},
$$

or

$$
E_{t}\left(\Delta_{k} s_{t+k}\right)=i_{t, k}-i_{t, k}^{*},
$$

where $E_{t}(\cdot)$ denotes the expectation based on information available at time $t$, and $\Delta_{k}=1-L^{k}$, with $L$ being the usual lag operator. Making use of (1) in (3) gives

$$
E_{t}\left(\Delta_{k} s_{t+k}\right)=f_{t, k}-s_{t},
$$

and therefore

$$
E_{t}\left(s_{t+k}\right)=f_{t, k} .
$$

Equation (5) is also known as the forward rate unbiasedness (FRU) hypothesis. Simple tests of the CIP and FRU hypotheses consist of inference on the coefficients of the following regressions:

$$
\Delta_{k} s_{t+k}=\alpha_{1}+\beta_{1}\left(f_{t, k}-s_{t}\right)+\epsilon_{1, t+k},
$$

and

$$
s_{t+k}=\alpha_{2}+\beta_{2} f_{t, k}+\epsilon_{2, t+k},
$$

where $\epsilon_{1, t+k}$ and $\epsilon_{2, t+k}$ are hypothesized white noise error terms.

Under UIP and FRU, $\alpha_{i}=0$ and $\beta_{i}=1, i=1,2$. Early analysis, such as that of Frenkel (1976), tended to use Equation (7) and the results appeared encouraging, with estimates of $\beta_{2}$ being found to be close to 1 . However, the results also had most of the hallmarks of the "spurious regression problem"; see Phillips (1986). Therefore, most of the next round of empirical work used Equation (6) as its basis, the seminal work being that of Fama (1984). Findings, based on a large variety of currencies and time periods, generally failed to accept UIP and the efficient market hypothesis; see, for example, Hodrick (1987), Lewis (1995), and Engel (1996). The estimates of $\beta_{1}$ obtained were usually negative and insignificantly different from zero. This negative estimate for $\beta_{1}$ is the main feature of the forward rate anomaly; it implies that the more the forward currency is at a premium in the forward market the less the home currency is predicted to depreciate.

\section{Explaining the anomaly}

To address the anomaly, subsequent empirical work was based on the developing econometric theory of the $I(1) / I(0)$ cointegration framework. It was argued by Engel (1996) that $s_{t}$ and $f_{t, k}$ are both $I(1)$, i.e., unit root series, and as such modelling should be undertaken using the error correction model (ECM). In terms of the two-step procedure of Engle and Granger (1987), the simple 
regression in Equation (7), as used by Frenkel to test the FRU hypothesis, can be viewed as the levels model. The corresponding ECM is then approximated by the slightly modified version of Equation (6) used by some investigators, namely,

$$
\Delta_{k} s_{t+k}=\alpha_{3}+\beta_{3}\left(f_{t, k}-s_{t}\right)+\boldsymbol{\delta}^{\prime} \mathbf{Q}_{t}+\epsilon_{3, t+k},
$$

where the vector $\mathbf{Q}_{t}$ includes lagged values of the $k$-period differences of the spot and forward exchange rates, and $\boldsymbol{\delta}$ is a vector of corresponding parameters. Despite improving the dynamic specification, this regression also yielded negative estimates of $\beta_{3}$.

This simple pseudo-ECM interpretation depends on both $s_{t}$ and $f_{t, k}$ being generated by $I(1)$ processes, and both the $\left\{s_{t+k}-s_{t}\right\}$ and $\left\{f_{t, k}-s_{t}\right\}$ series being $I(0)$. The empirical evidence on this is confusing. Barnhart and Szakmary (1991), Horvath and Watson (1994), and Hai, Nelson and Yangru (1997) all find evidence of unit roots in the series $\left\{s_{t}\right\}$ and $\left\{f_{t, k}\right\}$, and cointegration between the series. However, Crowder $(1994,1995)$, and Kuersteiner (1996) fail to reject the unit root hypothesis in several forward premia $\left(\left\{f_{t, k}-s_{t}\right\}\right)$ series ; and, using the Kwiatkowski, Phillips, Schmidt and Shin (1992) (KPSS) test, Crowder was also able to reject stationarity in both his data sets. Further, Zivot (2000) showed that if $s_{t}$ and $f_{t, 1}$ are cointegrated, the cointegrating model for $s_{t+1}$ and $f_{t, 1}$ is not a simple finite-order ECM and that estimating a first-order ECM for $s_{t+1}$ and $f_{t, 1}$ can lead to mistaken inferences concerning the exogeneity of the spot rate and the unbiasedness of the forward rate. Also of interest is that amongst those researchers investigating within the $I(1) / I(0)$ framework, some reported variations in the estimates of $\beta_{3}$ for subsamples, suggesting parameter instability; see Barnhart and Szakmary (1991), Naka and Whitney (1995), Engel (1996), and Baillie and Bollerslev (2000).

To address these issues, Baillie and Bollerslev (1994, 2000), and Maynard and Phillips (2001) investigated the effects on estimation if $\left\{s_{t+k}-s_{t}\right\}$ and $\left\{f_{t, k}-s_{t}\right\}$ are, as evidence suggests, a martingale difference sequence with high volatility and a highly autocorrelated, possibly long memory, process with low volatility, respectively. The form of the long memory considered was that of fractional integration.

A series $\left\{y_{t}\right\}_{t=0}^{\infty}$ is said to be integrated of order $d$, denoted by $I(d)$, if it has to be differenced $d$ times to induce stationarity. In classical analysis, $d$ is an integer, and the majority of empirical research has employed $d=1$ and the $I(1) / I(0)$ framework, in which either $y_{t}$ or $\Delta y_{t}=y_{t}-y_{t-1}$ is stationary. In fractional integration analysis, the restriction that $d$ is an integer is relaxed. This leads to a more general formula for an integrated series of order $d$, given by

$$
\begin{aligned}
\Delta^{d} y_{t}= & y_{t}-d y_{t-1}+\frac{1}{2 !} d(d-1) y_{t-2}-\frac{1}{3 !} d(d-1)(d-2) y_{t-3}+\ldots \\
& +\frac{(-1)^{j}}{j !} d(d-1) \ldots(d-j+1) y_{t-j}+\ldots
\end{aligned}
$$

In the case where $0<d<1$, it follows that not only the immediate past value of $y$ but values from previous time periods influence the current value. If 
$0<d<0.5$, then the series $\left\{y_{t}\right\}$ is stationary; and if $0.5 \leq d<1.0$, then $\left\{y_{t}\right\}$ is nonstationary.

In particular, Maynard and Phillips (2001), using both parametric and nonparametric estimation, found evidence of nonstationary long-memory behaviour of the forward premium. They went on to show how the implied imbalance in the traditional Fama-type regressions leads to nonstandard limiting distributions for the estimators and the test statistics. The slope and $R^{2}$ coefficients converge to zero, the $t$ statistic diverges and its left-tailed limiting distribution appears consistent with the forward rate anomaly. They also showed that regression in the levels would be fractionally cointegrated, with nonstationary residuals and a slope coefficient estimate that is consistent, but with a $t$ statistic that diverges. If the forward premium is indeed a long memory process, then the simple FRU hypothesis must be rejected.

Others pursued the issue of nonlinearities rather than nonstationarity to explain the forward exchange rate anomaly. One such approach has used Markovswitching models in an attempt to characterize exchange rate behaviour. Their use is based on the empirical observation that the conditional distribution of nominal exchange rate changes can be described by a mixture of normal distributions; see Boothe and Glassman (1987). However, in general, early versions of such models failed to produce better forecasts than more conventional linear models; see Engel (1994). One exception is to be found in the work of Engel and Hamilton (1990), who apply the Markov-switching model developed by Hamilton (1989) to dollar exchange rate data and show that the model generates better forecasts than a random walk. Interest in Markov-switching models has been regenerated in recent years with the use of Markov-switching ECMs; see Clarida, Sarno, Taylor and Valente (2003).

Various economic reasons for nonlinearity have been put forward over the years. The issue of transaction costs, as discussed by Baldwin (1990), Dumas (1992), and Hollifield and Uppal (1997), has attracted considerable attention, as has central bank intervention and the existence of limits to speculation; see Mark and Moh (2003) and Lyons (2001), respectively. Two of the most recent papers, by Sarno, et al. (2004) and Baillie and Kiliç (2005), have used the arguments surrounding the limit of speculation hypothesis to rationalize the use of smooth transition dynamic regression (STR) models. Introduced by Granger and Teräsvirta (1993), the general form of these models is

$$
\Delta_{k} s_{t+k}=\alpha_{4}+\beta_{4}\left(f_{t, k}-s_{t}\right)+\left[\alpha_{4}^{*}+\beta_{4}^{*}\left(f_{t, k}-s_{t}\right)\right] F\left(z_{t}, \gamma, c\right)+\epsilon_{4, t+k},
$$

where $z_{t}$ is the transition variable, $\gamma$ is a slope parameter and $c$ a location parameter.

Sarno, et al. (2004) used the exponential smooth transition regression (ESTR) to investigate nonlinearity in the Fama regression model (Equation(6)). This takes the form of Equation (10), with the function $F(\cdot)$ specified as

$$
F\left(z_{t}, \gamma, c\right)=\left\{1-\exp \left[-\gamma\left(z_{t}-c\right)^{2}\right]\right\},
$$

and $z_{t}$ being derived as the expected excess returns, using survey data on exchange rate expectations from Money Market Services. They also used the 
logistic smooth transition regression (LSTR), in which $F(\cdot)$ is defined as

$$
F\left(z_{t}, \gamma, c\right)=\left\{1+\exp \left[-\gamma\left(z_{t}-c\right) / \sigma_{z_{t}}\right]\right\}^{-1}
$$

with $\gamma>0$ and $\sigma_{z_{t}}$ denoting the standard deviation of the $z_{t}$ variable. They found that the ESTR fitted the data well and, using a RESET-type specification test due to Teräsvirta (1994) on the LSTR model, found strong evidence of nonlinearity.

In a completely separate study, Baillie and Kiliç (2005) investigate the use of the LSTR model with $z_{t}=\left(f_{t, 1}-s_{t}\right) / \sigma_{\left(f_{t, 1}-s_{t}\right)}$, i.e., the risk adjusted forward rate premium, to explain the forward rate anomaly. They point out that the ESTR imposes more strict symmetry requirements on the data than does the LSTR. In addition they warn that while the LSTR model seems to explain some of the nonlinear aspects of the anomaly it does not "tell the whole story".

\section{Testing for stationarity}

The empirical investigation of the forward exchange rate anomaly has been handicapped by a lack of appropriate econometric procedures. Inference is problematical in the fractionally integrated environment, as none of the normal procedures is appropriate. The classical asymptotics of the $I(0)$ case do not apply when the series are fractional, and neither does the conventional $I(1)$ approach, where the usual tests depend on the statistics converging to known functionals of Brownian motion. When $d \neq 1$, these are replaced by fractional Brownian motion. Early tests of fractional integration were based on the frequency domain approach of Robinson (1994); see Gil-Alana and Robinson (1997, 2001). In this approach, a semi-parametric test statistic is calculated for various values of $d$ and inference is made on the tabulated results. For further details and an application of the methodology to the forward rate anomaly, using the Canadian/US dollar exchange rate, see Gil-Alana (2002).

Testing for nonlinearity in a context of nonstationarity is also problematical. In Gil-Alana (2004), an attempt is made to extend the semiparametric approach of Robinson (1994) but this requires knowledge of the form of the nonlinearity. Other recent papers by Dolado, et al. (2005) and Mayoral (2005), consider testing for fractional integration against the alternative of stationarity and nonlinearity in the form of structural breaks.

In this paper, the usefulness of two recent tests in helping to explain the forward exchange rate anomaly are investigated. The first is the fractional augmented Dickey-Fuller (FADF) test introduced by Dolado, Gonzalo and Mayoral (2002), which is a simple-to-implement parametric test; and the second is the random field regression-based approach to testing for nonlinearities introduced by Hamilton (2001). The strength of Hamilton's approach is that it does not rely on any functional form being specified prior to estimation.

The Dolado, et al. (2002) approach to testing for fractionality is based on the 
' $t$ ' statistic associated with the estimate of $\phi$ in the generalized ADF regression

$$
\Delta^{d_{0}} y_{t}=\phi \Delta^{d_{1}} y_{t-1}+\sum_{i=1}^{p} \zeta_{i} \Delta y_{t-i}+v_{t},
$$

where $v_{t}$ is a hypothesized white noise error. For practical testing purposes, $d_{0}$ is set equal to 1 . The test of $H_{0}: \phi=0$ is then a test of the null hypothesis that the series $\left\{y_{t}\right\}$ is $I(1)$ against the alternative hypothesis that the series is $I(d)$. Dolado, et al. showed that if $0.5 \leq d_{1}<1$, then the ' $t$ ' statistic follows an asymptotic normal distribution under $H_{0}$, while if $0<d_{1}<0.5$, it follows a nonstandard distribution of fractional Brownian motion. However, they also showed that in the practically realistic case where $d_{1}$ is unknown, the ' $t$ ' statistic has an asymptotic normal distribution for $0 \leq d_{1}<1$, provided a $T^{-\frac{1}{2}}$-consistent estimator of $d_{1}$ is used.

\section{$5 \quad$ Testing for nonlinearity}

The idea of using random field regression models to estimate and test for nonlinear economic relationships was introduced by Hamilton (2001). This section contains an outline of Hamilton's approach.

If $\epsilon_{t}$ is an independent $N\left(0, \sigma^{2}\right)$ stochastic disturbance and $\mathbf{x}_{t}$ is a $k$-vector of explanatory variables, which may include lagged dependent variables, then the basic model is of the form

$$
y_{t}=\mu\left(\mathbf{x}_{t}\right)+\epsilon_{t},
$$

where the form of the conditional mean function $\mu\left(\mathbf{x}_{t}\right)$ is unknown and assumed to be the outcome of a Gaussian random field with a simple moving average representation. In his paper, Hamilton suggested representing $\mu\left(\mathbf{x}_{t}\right)$ as consisting of two components. The first is the usual linear component, while the second is a nonlinear component that is treated as stochastic and hence unobservable. Both the linear and nonlinear components contain unknown parameters that need to be estimated. Thus the conditional mean function is written as

$$
\mu\left(\mathbf{x}_{t}\right)=\alpha_{0}+\boldsymbol{\alpha}^{\prime} \mathbf{x}_{t}+\lambda m\left(\overline{\mathbf{x}}_{t}\right),
$$

where $\overline{\mathbf{x}}_{t}=\mathbf{g} \odot \mathbf{x}_{t}, \mathbf{g}$ is a $k$-vector of parameters and $\odot$ denotes the Hadamard product. The function $m\left(\overline{\mathbf{x}}_{t}\right)$ is referred to as the random field. Hamilton showed that even under fairly general misspecification, it is possible to obtain consistent estimators of the conditional mean. In addition, Dahl (2002) has shown that the random field approach has relatively better small sample fitting abilities than a wide range of parametric and nonparametric alternatives, including the LSTR and ESTR models mentioned in Section 3. Further results on the consistency of the parametric estimators obtained from this approach are given by Dahl, González-Rivera and Qin (2005).

By choosing $m\left(\overline{\mathbf{x}}_{t}\right)$ to be a realization of a homogeneous and isotropic Gaussian random field that is described by its first two moments, Hamilton showed that 
estimating the unknown parameters $\boldsymbol{\varphi}=\left\{\alpha_{0}, \boldsymbol{\alpha}, \mathbf{g}, \lambda, \sigma^{2}\right\}$ can be reduced to maximum likelihood estimation of a reparameteristaion of (14) and (15). Thus he defined

$$
m\left(\overline{\mathbf{x}}_{t}\right) \sim N(0,1)
$$

and

$$
E\left(m\left(\overline{\mathbf{x}}_{t}\right)^{\prime} m\left(\overline{\mathbf{x}}_{s}\right)\right)=H_{k}(h),
$$

where $h$ is defined as the $L_{2}$ norm $h=\frac{1}{2}\left[\left(\overline{\mathbf{x}}_{t}-\overline{\mathbf{x}}_{s}\right)^{\prime}\left(\overline{\mathbf{x}}_{t}-\overline{\mathbf{x}}_{s}\right)\right]^{\frac{1}{2}}$. Dahl and González-Rivera (2003), and Dahl and Hylleberg (2004), investigate the use of the alternative $L_{1}$ norm and show that it largely overcomes the problem of unidentified nuisance parameters.

The covariance $H_{k}(h)$ is defined by Hamilton as

$$
H_{k}(h)=\left\{\begin{array}{ll}
\frac{G_{k-1}(h, 1)}{G_{k-1}(0,1)} & h \leqslant 1 \\
0 & h>1
\end{array},\right.
$$

where $G_{k}(h, r)(0<h \leq r)$ is

$$
G_{k}(h, r)=\int_{h}^{r}\left(r^{2}-z^{2}\right)^{\frac{1}{2}} d z .
$$

So (14) can be rewritten as:

$$
y_{t}=\alpha_{0}+\boldsymbol{\alpha}^{\prime} \mathbf{x}_{t}+u_{t}
$$

where

$$
u_{t}=\lambda m\left(\overline{\mathbf{x}}_{t}\right)+\epsilon_{t},
$$

or, in matrix form,

$$
\mathbf{y}=\mathbf{X} \boldsymbol{\beta}+\mathbf{u}
$$

where $\boldsymbol{\beta}=\left[\alpha_{0}, \boldsymbol{\alpha}^{\prime}\right]^{\prime}$ and

$$
\mathbf{u} \sim N\left(\mathbf{0}, \lambda^{2} \mathbf{H}+\sigma^{2} \mathbf{I}_{T}\right)
$$

Treating the estimation of (17) and (18) as a generalized least squares problem, and letting $\zeta=\frac{\lambda}{\sigma}$, the associated profile maximum likelihood function can be obtained as

$$
\eta(\mathbf{y}, \mathbf{X} ; \mathbf{g}, \zeta)=-\frac{T}{2} \ln (2 \pi)-\frac{T}{2} \ln \sigma^{2}(\mathbf{g}, \zeta)-\frac{1}{2} \ln |\mathbf{W}(\mathbf{X} ; \mathbf{g}, \zeta)|-\frac{T}{2},
$$

and

$$
\begin{gathered}
\widetilde{\boldsymbol{\beta}}(\mathbf{g}, \zeta)=\left[\mathbf{X}^{\prime} \mathbf{W}(\mathbf{X} ; \mathbf{g}, \zeta)^{-1} \mathbf{X}\right]^{-1}\left[\mathbf{X}^{\prime} \mathbf{W}(\mathbf{X} ; \mathbf{g}, \zeta)^{-1} \mathbf{y}\right], \\
\widetilde{\sigma}^{2}(\mathbf{g}, \zeta)=\frac{1}{T}[\mathbf{y}-\mathbf{X} \widetilde{\boldsymbol{\beta}}(\mathbf{g} ; \zeta)]^{\prime} \mathbf{W}(\mathbf{X} ; \mathbf{g} ; \zeta)^{-1}[\mathbf{y}-\mathbf{X} \widetilde{\boldsymbol{\beta}}(\mathbf{g} ; \zeta)],
\end{gathered}
$$

where $\mathbf{W}(\mathbf{X} ; \mathbf{g}, \zeta)=\zeta^{2} \mathbf{H}+\sigma^{2} \mathbf{I}_{T}$. The profile likelihood can be maximized with respect to $(\mathbf{g}, \zeta)$ using standard algorithms, though as Bond, Harrison and 
O'Brien (2005) point out, care needs to be taken due to potential computational complications. Once estimates for $\mathbf{g}$ and $\zeta$ have been obtained, equations (20) and (21) can be used to obtain estimates of $\boldsymbol{\beta}$ and $\sigma$.

The random field model (15) suggests that a simple approach to checking for nonlinearity is to test the null hypothesis $H_{0}: \lambda=0$, using the Lagrange multiplier principle. Hamilton (2001) derived the appropriate score vector of first derivatives and the associated information matrix. Details of the procedure are given by Hamilton (2001), and summarized in Bond, et al. (2005), but the main steps of the test are presented here for convenience.

- Set $g_{i}=\frac{2}{\sqrt{k s_{i}^{2}}}$, where $s_{i}^{2}$ is the variance of explanatory variable $x_{i}$, excluding the constant term whose variance is zero.

- Calculate the $T \times T$ matrix, $\mathbf{H}$, whose typical element is $H_{k}\left(\frac{1}{2}\left\|\overline{\mathbf{x}}_{t}-\overline{\mathbf{x}}_{s}\right\|\right)$, i.e., the function $H_{k}(h)$ defined above.

- Use OLS to estimate the standard linear regression $\mathbf{y}=\mathbf{X} \boldsymbol{\beta}+\mathbf{u}$ and obtain the residuals, $\widehat{\mathbf{u}}$, and standard error of estimate, $\widehat{\sigma}^{2}=(T-k-1)^{-1} \widehat{\mathbf{u}}^{\prime} \widehat{\mathbf{u}}$.

- Finally, compute the statistic

$$
\varkappa^{2}=\frac{\left[\widehat{\mathbf{u}}^{\prime} \mathbf{H} \widehat{\mathbf{u}}-\widehat{\sigma}^{2} \operatorname{tr}(\mathbf{M H})\right]^{2}}{\widehat{\sigma}^{4}\left\{2 \operatorname{tr}\left(\left[\mathbf{M H M}-(T-k-1)^{-1} \mathbf{M} \operatorname{tr}(\mathbf{M H})\right]^{2}\right)\right\}},
$$

where $\mathbf{M}=\mathbf{I}_{T}-\mathbf{X}\left(\mathbf{X}^{\prime} \mathbf{X}\right)^{-1} \mathbf{X}^{\prime}$ is the familiar symmetric idempotent matrix.

As $\varkappa^{2} \stackrel{A}{\sim} \chi_{1}^{2}$ under the null hypothesis, linearity $(\lambda=0)$ would be rejected if $\varkappa^{2}$ exceeded the critical value, $\chi_{1, \alpha}^{2}$, for the chosen level of significance, $\alpha$. Otherwise the null of linearity would not be rejected. For example, at the 5 per cent significance level, the null would be rejected if $\varkappa^{2}>3.84$.

A trio of alternative random field-based tests is provided by Dahl and GonzálezRivera (2003).

\section{Approach adopted in this paper}

To investigate the usefulness of both the Dolado et al. FADF test and the Hamilton random field regression approach in helping explain the forward rate anomaly, this paper applies the two techniques to the cross exchange rates for sterling and the Australian dollar, sterling and the Canadian dollar, and sterling and the Japanese yen. In each case, the data used are daily series for the period $30^{\text {th }}$ December 1994 to $16^{\text {th }}$ June 2005, inclusive, which were downloaded from Datastream. For purposes of comparison, the study starts with the standard $I(1) / I(0)$ analysis, using the ADF test conducted according to the strategy of Dolado, Jenkinson and Sosvilla-Rivero (1990) to determine whether the series are trend stationary or difference stationary. The lag length for the ADF test is determined by means of the modified Akaike information criterion (MAIC), 
which Ng and Perron (2001) have shown to be a generally better decision criterion than the standard AIC as it takes account of the persistence found in many series. The KPSS and Ng-Perron (NP) alternative unit root tests are also applied, the latter being generally more powerful against the alternative of fractional integration than the standard ADF test, as Perron and Ng (1996) have shown. As well as testing the individual exchange rate and exchange premium series, unit root tests are also carried out on the ordinary least squares residuals from a number of static regressions to assess the possibility of cointegration.

Following this traditional analysis, the issue of fractional integration is investigated. Two approaches to applying the FADF test have emerged in the literature. The first, following Hansen (1999), is to apply the test for various values of $d \in[0,1)$ and either tabulate or plot the results before making any inferences; see Heravi and Patterson (2005). The second is to obtain a consistent parametric estimate of $d$, as suggested by Dolado et al. (2002), and apply the FADF test for this value. It is the second of these approaches that is used in this paper. Following the recommendation of Smith, Sowell and Zin (1997), the 'over-differenced' ARFIMA model, employing $\Delta y_{t}$ rather than $y_{t}$, is estimated to avoid the problems associated with drift.

Two parametric estimates of $d$ are calculated, using the ARFIMA package of Doornik and Ooms (1999). One is the exact maximum likelihood (EML) estimate produced by the algorithm suggested by Sowell (1992), which requires that $d<0.5$ and, hence, provides another reason for using the 'over-differenced' model. The other is an approximate maximum likelihood estimate based on the conditional sum of squared näive residuals developed by Beran (1995), and called a nonlinear least squares (NLS) estimate by Doornik and Ooms. The parametric estimates of $d$ are then used in the FADF test, with the MAIC again being used to set the lag length of the test. To investigate the results of Maynard and Phillips (2001) and Zivot (2000), equations (6) and (7) are estimated and the order of integration of the respective estimated error terms explored. For Equation (7), both $s_{t}$ and $s_{t+k}$ are regressed on $f_{t, k}$.

For interest, the nonparametric estimates of $d$ from the log-periodogram regression method of Geweke and Porter-Hudak (1983) (GPH), and the semiparametric estimates from the Gaussian method (GSP) discussed in Robinson and Henry (1998), are also computed. Both of these complementary approaches are also available in the Doornik and Ooms (1999) ARFIMA package.

Finally, the random field regression approach is applied to the data. To do this, the Gauss program code provided by Hamilton at http://weber.ucsd.edu/ jhamilto is used. Given the large size of the dataset, the approach of Hansen and Hodrick (1980) is adopted to ease the considerable computational burden involved in the random field analysis. Weekly data points are chosen, using every fifth observation. 


\section{Results}

The results of the preliminary unit root tests are given in Table $1 .{ }^{1}$ The Dolado et al. (1990) testing strategy failed to support the existence of a trend or drift in all cases, so the $p$-values given in Table 1 are those from the tables provided by MacKinnon (1996). The KPSS, and to some extent the NP test results, were sensitive to the choice of spectral estimator used. This was especially true for the spot premium in each of the three cases.

Bearing in mind the different null hypothesis of the KPSS test, a clear picture emerges from Table 1. In all three cases considered, the ADF test does not suggest rejection of the null hypothesis of a unit root in the forward exchange rate, the spot rate and the forward premium, but it does point to clear rejection of the unit root null for all three spot premiums. Moreover, apart from the sensitivity difficulty in connection with the spot premiums alluded to above, the KPSS and NP tests provide unambiguous confirmation of this finding.

Table 2 contains the results of the fractional integration analysis. The FADF test fails to reject the null hypothesis that the spot and forward rates are $I(1)$ against the alternative of fractional integration, in agreement with the findings of Heravi and Patterson (2005). However, from this table it can be seen that in all cases it is unlikely that the forward premium is either $I(1)$ or $I(0)$. Whereas the ADF test could not reject the $I(1)$ hypothesis, the FADF test clearly rejects it, if the EML estimate of $d$ is used for the alternative hypothesis. It therefore seems very likely that the forward premium is $I(d)$, where $0<d<1$. The weight of evidence from the parametric estimators is that $d$ is around 0.5.

Estimation and testing of the value of $d$ for the spot premium proved interesting. Given the ADF results in Table 1, it would seem reasonable to assume that $d$ is close to zero. However, both ARFIMA and semiparametric estimates of $d$ are close to unity. Only by specifying a nontrivial $A R$ and $M A$ component were values of $d$ insignificantly different from zero possible. In the Japanese yen case, only when switching from the over-differenced ARFIMA to a simple linear model did estimates of $d$ appear to be insignificantly different from zero. The converse seems to be true for the forward premium, for which Table 1 suggests a value of $d$ close to one, while the corresponding results in Table 2 suggest a much lower value of $d$. The values of $d$ obtained for the forward premium are more in line with those reported by Baillie and Bollerslev (1994) than those found by Maynard and Phillips (2001).

The results for the standard regression models (6) and (7) are presented in Table 3 . The estimated coefficients are generally in line with the corresponding results from previous studies. However, the unit root tests on the residuals from these regressions are slightly confusing. In two cases, namely, the second regression for the sterling-Australian dollar data and the second regression for the sterling-Japanese yen data, the ADF and NP test results are in conflict, with the former suggesting rejection of the unit root null and the latter suggesting nonrejection. This is surprising, given the likely superior power of the NP test.

\footnotetext{
${ }^{1}$ All tables are presented in the Appendix.
} 
Similarly, there are two regressions for which the findings of the ADF and KPSS tests are different: again, the second regression for the sterling-Australian dollar data and also the first regression for the sterling-Canadian dollar data. In light of the earlier unit root test results in Table 1, it is difficult to conclude from Table 3, using the standard Engle-Granger approach, that any of the levels regressions may constitute a cointegrating regression.

Table 4 presents estimates of $d$ obtained from the four alternative methods of estimation applied to the residuals from the regressions reported in Table 3. The results obtained are broadly in line with the theory given in Maynard and Phillips (2001). While estimates of $d$ for the residuals of all three $s_{t}$ on $f_{t, k}$ regressions are generally small, those from the other two regressions are considerably larger in the three cases. Correspondingly, the FDF and FADF tests clearly reject the $I(1)$ null in favour of the alternative of fractional integration for the residuals of all regressions of $s_{t}$ on $f_{t, k}$, and for the residuals of the sterling-Canadian dollar regression of $s_{t+k}$ on $f_{t, k}$. This latter rejection of the null appears to be in accord with the corresponding result in Table 3 . However, in the case of Table 4 , the indication is clearly that the alternative is $0.5<d<1$, rather than $0 \leqslant d \leqslant 0.5$, though $I(0)$ is the conclusion from the Engle-Granger type of analysis. There is one case of clear disagreement between the unanimous finding of the unit root tests in Table 3 and the corresponding result in Table 4. This is the regression of $\Delta_{k} s_{t+k}$ on $\left\{f_{t, k}-s_{t}\right\}$, for which the standard unit root tests strongly suggest rejection of the unit root null, while the fractional tests indicate nonrejection.

The results from the Hamilton analysis are given in Table 5. In producing these results, which relate to the sterling-Canadian dollar data, two variants of models (6) and (7) were employed. After some exploratory checking of crossplots, a time trend was included in both equations, and they were estimated with and without a constant. For computational convenience, some rescaling of the data was undertaken and an algorithm-switching strategy was used in the numerical optimization. Specifically, the observations on the explanatory variable $f_{t, k}$ were scaled up by a factor of ten, while switching between the Gauss algorithms Steep and Newton was used, along with selected initial values of $\zeta$, ranging from 0.1 to 1.9 , and the default value of the Gauss parameter oprteps; see Bond et al. (2005) for further details on this approach to the Hamilton computations. Furthermore, both the original Hamilton covariance matrix, and the Dahl and González-Rivera (2003) forms of the covariance matrix for the random field were utilized. The number of iterations required to determine the maximum likelihood estimates ranged from 11 to 28 .

There is overwhelming evidence of nonlinearity in these models, with the Hamilton Lagrange multiplier test statistics ranging from 381.46 to 4406.01. The alternative tests of Dahl and González-Rivera produced very similar results. As can be seen from the Table 5, the nonlinearity in the equations is consistently associated with the time variable, which has a statistically significant coefficient in the nonlinear component of all four models. The plots in figures 1 and 2 in the Appendix give an indication of the time-wise nonlinearity. For the exchange rate relationship, Figure 1 suggests an upward trend switching to a downward 
trend in the early part of the sample, with reasonable constancy thereafter. For the exchange premium relationship, by contrast, the suggestion is of cyclical, if somewhat erratic, changes throughout the sample period.

A feature of the Hamilton results is the high significance of the $\sigma$ and $\zeta$ estimates in the equations for exchange rates, and the contrasting lack of significance of these estimates in the equations for premiums, even though the latter estimates are much bigger numerically. It seems reasonable to assume that these particular insignificant results are related to what, in the time series literature, is known as the "pile up" phenomenon associated with numerical optimization, and that this may signal that the covariance structure used for the random field, if not the normality assumption itself, may not be entirely appropriate; see DeJong and Whiteman (1993) and Hamilton (2005).

However, the most significant aspect of the Hamilton analysis is that it shows that when nonlinearity is allowed for by means of a random field in the exchange rate equation, the intercept is not significantly different from zero and the slope coefficient is estimated, with great precision, to be unity, in accordance with exchange rate theory. Similarly, in the exchange premium equation, the intercept and slope are not significantly different from zero and unity, respectively, though as the standard errors are larger in this case, the result is not quite as striking as it is for the rate equation. Modelling nonlinearity using the Hamilton method seems to remove the forward anomaly.

\section{Conclusion}

This paper has focussed on the well-known foreign exchange rate anomaly, brought to prominence by Fama (1984). It has given brief descriptions of the anomaly, the main early approaches that were used in trying to explain it, the idea of fractional integration that underlies some recent attempts at explanation using long memory time-series models, and the forms of the smooth transition regression model that have been employed in other recent research to investigate the role of nonlinearity. In particular, it has drawn attention to the theoretical work by Dolado et al. (2002) on testing for fractional integration, and that of Hamilton (2001) on random field regression and nonlinear inference, as developments that offer relevant new approaches to the study of the anomaly. Finally, to illustrate and assess the usefulness of these two new methods, the paper reports on an investigation of their application to three sets of exchange rate and exchange premium data. The main findings are as follows.

Firstly, in all three cases considered, the standard $I(1) / I(0)$ approach to testing for unit roots and cointegration suggests that spot and forward exchange rates, as well as the forward exchange premium, behave as nonstationary $I(1)$ series, and that the spot premium is $I(0)$. Furthermore, given the disagreement amongst the ADF, KPSS and NP tests when applied to the residuals of static regressions, there are mixed findings on the possibility of cointegration; the possibility is clearer in the sterling-Canadian dollar case.

Secondly, while the results of the fractional integration analysis accord with 
the finding that spot and forward rates are $I(1)$, they contradict those of the standard analysis with regard to the properties of the exchange premiums. Whereas the ADF and other unit root tests suggest that $d=1$ for the forward premium, EML and other estimates indicate a value closer to $d=0.5$, and the FDF and FADF tests give a strong rejection of the unit root null hypothesis. Similarly, rejection of the unit root null in the standard analysis suggests that the spot premium may be treated as $I(0)$, while fractional parameter estimation indicates that $d$ is fairly close to unity. This latter conflict is very puzzling and deserves attention in any future research, perhaps using the new test of Dolado et al. (2005), which would permit testing of the null hypothesis that a series is $I(0)$ against the alternative that it is fractionally integrated.

Thirdly, similar discrepancies emerge between the outcomes of standard unit root tests and the fractional analysis when the ordinary least squares residuals from a variety of regressions are examined. The FDF and FADF tests tend to support the standard tests with regard to their finding that the unit root null should be rejected for the residuals, but the fractional analysis suggests that $0<d<1$, calling into question the standard conclusion that the residuals may be deemed to be $I(0)$.

Fourthly, there are strong indications of time-dependent nonlinearity when the sterling-Canadian dollar data are subjected to examination using the Hamilton nonlinearity test and random field regression procedure. The nonlinearity in the relationship between exchange rates appears to be of a very different form from that in the relationship between exchange premiums. However, it is of considerable interest that in both cases, when the nonlinearity is modelled by means of a random field, exchange rate theory is confirmed and the forward rate anomaly removed. This key finding adds weight to the earlier work on the relevance of instability to the forward anomaly debate referred to in Section 3. It points clearly to the possibility that the exchange rate series examined may be $I(0)$ with structural breaks, and that fractional integration tests, as well as standard unit root tests, are sensitive to this. 


\section{References}

Baillie, R. T., And T. Bollerslev (1994): "Cointegration, Fractional Cointegration and Exchange Rate Dynamics," Journal of Finance, 49, 737-745.

(2000): "The Forward Permium Anomaly is Not as Bad as You Think," Journal of International Money and Finance, 19, 471-488.

Baillie, R. T., And R. Kiliç (2005): "Do Asymmetric and Nonlinear Adjustments Explain the Forward Premium Anomaly?," Working Paper No. 543, Department of Economics, Queen Mary College, University of London.

BALdwin, R. E. (1990): "Re-Interpreting the Failure of Foreign Exchange Market Efficiency Tests: Small Transaction Costs, Big Hysteresis Bands," Discussion Paper No. 3319, National Bureau of Economic Research.

Barnhart, S. W., and A. C. Szakmary (1991): "Testing the Unbiased Forward Rate Hypothesis: Evidence on Unit Roots, Cointegration and Stochastic Coefficients," Journal of Financial and Quantitative Analysis, 26, 245-267.

Beran, J. (1995): "Maximum Likelihood Estimation of the Differencing Parameter for Invertible Short and Long Memory Autoregressive Integrated Moving Average Models," Journal of the Royal Statistical Society, Series B, 57, 659-672.

Bond, D., M. J. Harrison, and E. J. O'Brien (2005): "Investigating Nonlinearity: A Note on the Estimation of Hamilton's Random Field Regression Model," Studies in Nonlinear Dynamics and Econometrics, 9, Article 2.

Boothe, P., and D. Glassman (1987): "Off the Mark: Lessons for Exchange Rate Modelling," Oxford Economic Papers, 39, 443-457.

Clarida, R. H., L. Sarno, M. P. Taylor, and G. Valente (2003): "The Out-of-Sample Success of Term Structure Models as Exchange Rate Predictors: A Step Beyond," Journal of International Economics, 60, 61-83.

Crowder, W. J. (1994): "Foreign Exchange Market Efficiency and Common Stochastic Trends," Journal of International Money and Finance, 13, 551564 .

Crowder, W. J. (1995): "Covered Interest Parity and International Capital Market Efficiency," International Review of Economics and Finance, 4, 115132.

DAHL, C. M. (2002): "An Investigation of Tests for Linearity and the Accuracy of Likelihood Based Inference Using Random Fields," Econometrics Journal, $5,263-284$.

Dahl, C. M., and G. GonzÁlez-Rivera (2003): "Testing for Neglected Nonlinearity in Regression Models Based on the Theory of Random Fields," Journal of Econometrics, 114, 141-164.

Dahl, C. M., G. GonzÁlez-Rivera, and Y. Qin (2005): "Statistical Inference and Prediction in Nonlinear Models using Additive Random Fields," Working Paper, Department of Economics, Purdue University.

Dahl, C. M., and S. Hylleberg (2004): "Flexible Regression Models and Relative Forecast Performance," International Journal of Forecasting, 20, $201-217$. 
DeJong, D. N., and C. H. Whiteman (1993): "Estimating Moving Average Parameters: Classical Pileups and Bayesian Posteriors," Journal of Business and Economic Statistics, 11, 311-317.

Diebold, F. X., And A. Inoue (2001): "Long Memory and Regime Switching," Journal of Econometrics, 105, 131-159.

Dolado, J. J., J. Gonzalo, and L. Mayoral (2002): "A Fractional DickeyFuller Test for Unit Roots," Econometrica, 70, 1963-2006.

(2005): "What is What?: A Simple Test of Long Memory vs Structural Breaks in the Time Domain," Working Paper, Universitat Pompeu Fabra.

Dolado, J. J., T. Jenkinson, and S. Sosvilla-Rivero (1990): "Cointegration and Unit Roots," Journal of Economic Surveys, 4, 249-273.

Doornik, J., And M. Ooms (1999): "A Package for Estimating, Forecasting and Simulating ARFIMA Models: ARFIMA Package 1.0 for Ox," Discussion Paper, Nuffield College, Oxford.

Dumas, B. (1992): "Dynamic Equilibrium and the Real Exchange Rate in a Spatially Separated World," Review of Financial Studies, 5, 153-180.

Engel, C. (1994): "Can the Markov Switching Model Forecast Exchange Rates?," Journal of International Economics, 36, 151-165.

(1996): "The Forward Discount Anomaly and the Risk Premium: A Survey of Recent Evidence," Journal of Empirical Finance, 3, 123-192.

Engel, C., And J. D. Hamilton (1990): "Long Swings in the Dollar: Are They in the Data and Do Markets Know It?," American Economic Review, $80,689-713$.

Engle, R. F., and C. W. J. Granger (1987): "Cointegration and Error Correction: Representation, Estimation and Testing," Econometrica, 55, 251276.

FAMA, E. (1984): "Forward and Spot Exchange Rates," Journal of Monetary Economics, 14, 319-338.

Frenkel, J. A. (1976): "A Monetary Approach to the Exchange Rate: Doctrinal Aspects and Empirical Evidence," Scandinavian Journal of Economics, $78,200-224$.

Geweke, J. F., and S. Porter-Hudak (1983): "The Estimation and Application of Long Memory Time Series Models," Journal of Time Series Analysis, 4, 221-238.

Gil-AlanA, L. A. (2002): "Empirical Evidence of the Spot and the Forward Exchange Rates in Canada," Economics Letters, 77, 405-409.

(2004): "A Joint Test of Fractional Integration and Structural Breaks at a Known Period of Time," Journal of Time Series Analysis, 25, 691-700.

Gil-Alana, L. A., and P. M. Robinson (1997): "Testing of Unit Root and Other Nonstationary Hypotheses in Macroeconomic Time Series," Journal of Econometrics, 80, 241-268.

(2001): "Testing of Seasonal Fractional Integration in UK and Japanese Consumption and Income," Journal of Applied Econometrics, 16, 95-114. 
Granger, C. W. J., And T. Teräsvirta (1993): Modelling Nonlinear Economic Relationships. Oxford University Press, Oxford.

Hai, E., M. Nelson, And W. Yangru (1997): "Understanding Spot and Forward Exchange Rate Regressions," Journal of Applied Econometrics, 12, $715-734$.

Hamilton, J. D. (1989): "A New Approach to the Economic Analysis of Nonstationary Time Series and the Business Cycle," Econometrica, 57, 357-384.

Hamilton, J. D. (2001): "A Parametric Approach to Flexible Nonlinear Inference," Econometrica, 69, 537-573.

Hamilton, J. D. (2005): "Comment on 'Investigating Nonlinearity'," Studies in Nonlinear Dynamics and Econometrics, 9, Article 3.

Hansen, B. E. (1999): "The Grid Bootstrap and the Autoregressive Model," Review of Economics and Statistics, 81, 594-607.

Hansen, L. P., And R. J. Hodrick (1980): "Forward Exchange Rates as Optimal Predictors of Future Spot Rates: An Econometric Analysis," Journal of Political Economy, 88, 829-853.

Harrison, M. J., And D. Bond (1992): "Testing and Estimation in Unstable Dynamic Models: A Case Study," Economic and Social Review, 24, 25-49.

Heravi, S., And K. Patterson (2005): "Optimal and Adaptive SemiParametric Narrowband and Broadband and Maximum Likelihood Estimation of the Long-Memory Parameter for Real Exchange Rates," Manchester School, 73, 165-213.

HodrICK, R. J. (1987): The Empirical Evidence on the Efficiency of Forward and Futures Foreign Exchange Markets. Harwood, London.

Hollifield, B., AND R. UPPAL (1997): "An Examination of Uncovered Interest Rate Parity in Segmented International Commodity Markets," Journal of Finance, 52, 2145-2170.

Horvath, M. T. K., and M. W. Watson (1994): "Testing for Cointegration when some of the Cointegrating Vectors are Known," Technical Working Paper No. 171, National Bureau of Economic Research.

Hsu, C. C. (2001): "Change Point Estimation in Regressions with $I(d)$ Variables," Economics Letters, 70, 147-155.

Krämmer, W., and P. Sibbertsen (2002): "Testing for Structural Changes in the Presence of Long Memory," International Journal of Business and Economics, 1, 235-242.

Kuersteiner, G. M. (1996): "Net Present Value Models for Exchange Rates," Working Paper, Department of Economics, Yale University.

Kwiatkowski, D., P. C. B. Phillips, P. Schmidt, and Y. Shin (1992): "Testing the Null Hypothesis of Stationarity Against the Alternative of a Unit Root," Journal of Econometrics, 54, 159-178.

LEwIS, K. K. (1995): "Puzzles in International Financial Markets," in The Handbook of International Economics, ed. by G. M. Grossman, and K. Rogoff, vol. 3, pp. 1913-1971. Elsevier North Holland, Amsterdam. 
Lyons, R. K. (2001): The Microstructure Approach to Exchange Rates. MIT Press, Cambridge, Mass.

MacKinnon, J. G. (1996): "Numerical Distribution Functions for Unit Root and Cointegration Tests," Journal of Applied Econometrics, 11, 601-618.

Mark, N., AND Y. K. MoH (2003): "Official Interventions and Occasional Violations of Uncovered Interest Party in the Dollar-DM Market," Discussion Paper No. 9948, National Bureau of Economic Research.

Maynard, A., and P. C. B. Phillips (2001): "Rethinking an Old Empirical Puzzle: Econometric Evidence on the Forward Discount Anomaly," Journal of Applied Econometrics, 16, 671-708.

Mayoral, L. (2005): "Is the Observed Persistence Spurious or Real? A Test for Fractional Integration versus Short Memory and Structural Breaks," Working Paper, Universitat Pompeu Fabra.

NAKA, A., and G. Whitney (1995): "The Unbiased Forward Rate Hypothesis Re-Examined," Journal of International Money and Finance, 14, 857-867.

NG, S., And P. Perron (2001): "Lag Length Selection and the Construction of Unit Root Tests with Good Size and Power," Econometrica, 69, 1519-1554.

Perron, P. (1989): "The Great Crash, the Oil Price Shock and the Unit Root Hypothesis," Econometrica, 57, 1361-1401.

Perron, P., And S. NG (1996): "Useful Modifications to Some Unit Root Tests with Dependent Errors and their Local Asymptotic Properties," Review of Economic Studies, 63, 435-463.

Perron, P., And Z. QU (2004): "An Analytical Evaluation of the LogPeriodogram Estimate in the Presence of Level Shifts and its Implication for Stock Market Volatility," Working Paper, Department of Economics, Boston University.

Phillips, P. C. B. (1986): "Understanding Spurious Regressions in Econometrics," Journal of Econometrics, 33, 311-340.

Robinson, P. M. (1994): "Efficient Tests of Nonstationary Hypotheses," Journal of the American Statistical Association, 89, 1420-1437.

Robinson, P. M., And M. Henry (1998): "Long and Short Memory Conditional Hetroscedasticity in Estimating the Memory Parameter of Levels," Econometric Theory, 15, 299-336.

SARno, L. (2005): "Towards a Solution to the Puzzles in Exchange Rate Economics: Where Do We Stand?," Canadian Journal of Economics, 35, 673708.

Sarno, L., and M. P. Taylor (2003): The Economics of Exchange Rates. Cambridge University Press, Cambridge, UK.

Sarno, L., G. Valente, and L. Hyginus (2004): "The Forward Bias Puzzle and Nonlinearity in Deviations from Uncovered Interest Parity: New Perspectives," University of Warwick and International Monetary Fund Mimeograph.

Smith, A. A., F. Sowell, and S. E. ZIN (1997): "Fractional Integration with Drift: Estimation in Small Samples," Empirical Economics, 22, 103-116. 
SowELL, F. (1992): "Maximum Likelihood Estimation of Stationary Univariate Fractionally Integrated Time Series Models," Journal of Econometrics, 53, 165-188.

TerÄsvirta, T. (1994): "Specification, Estimation and Evaluation of Smooth Transition Autoregressive Models," Journal of the American Statistical Assocaition, 89, 208-118.

Zivot, E. (2000): "Cointegration and Forward and Spot Exchange Rate Regressions," Journal of International Money and Finance, 19, 785-812. 


\section{A Appendices}

\section{A.1 Tables}

Table 1: Unit Root Tests

\begin{tabular}{|c|c|c|c|c|c|}
\hline VARIABLES & $\mathrm{ADF}$ & $P$-value & No. of Lags & $\mathrm{KPSS}^{\dagger}$ & $\mathrm{NP}^{\dagger}$ \\
\hline \multicolumn{6}{|c|}{ Australian Dollar } \\
\hline Forward Rate & 0.089 & 0.71 & 0 & Yes & No \\
\hline Spot Rate & 0.043 & 0.70 & 2 & Yes & No \\
\hline Forward Premium & -1.32 & 0.17 & 20 & Yes & No \\
\hline Spot Premium & -4.52 & 0.000 & 2 & see text & Yes \\
\hline \multicolumn{6}{|c|}{ CANADIAN DOLLAR } \\
\hline Forward Rate & -0.13 & 0.64 & 5 & Yes & No \\
\hline Spot Rate & -0.10 & 0.65 & 0 & Yes & No \\
\hline Forward Premium & -1.23 & 0.20 & 12 & Yes & No \\
\hline Spot Premium & -5.42 & 0.000 & 0 & see text & Yes \\
\hline \multicolumn{6}{|c|}{ JAPANESE YEN } \\
\hline Forward Rate & 0.65 & 0.86 & 5 & Yes & No \\
\hline Spot Rate & 0.65 & 0.86 & 1 & Yes & No \\
\hline Forward Premium & -0.43 & 0.53 & 14 & Yes & No \\
\hline Spot Premium & -4.01 & 0.001 & 0 & see text & Yes \\
\hline
\end{tabular}

$\dagger$ Yes - significant at 5 per cent level. No - not significant at 5 per cent level. 
Table 2: Fractional Integration Analysis

\begin{tabular}{|c|c|c|c|c|c|c|}
\hline VARIABLES & EML & NLS & GPH & GSP & FDF & FADF \\
\hline \multicolumn{7}{|c|}{ Australian Dollar } \\
\hline Forward Rate & $\begin{array}{c}0.99 \\
(0.017)\end{array}$ & $\begin{array}{c}0.99 \\
(0.017)\end{array}$ & $\begin{array}{c}0.99 \\
(0.020)\end{array}$ & $\begin{array}{c}0.97 \\
(0.015)\end{array}$ & 0.31 & -1.07 \\
\hline Spot Rate & $\begin{array}{l}0.97 \\
(0.017)\end{array}$ & $\begin{array}{c}0.97 \\
(0.017)\end{array}$ & $\begin{array}{c}0.99 \\
(0.020)\end{array}$ & $\begin{array}{l}0.97 \\
(0.015)\end{array}$ & -0.42 & -1.33 \\
\hline Forward Premium & $\begin{array}{c}0.56 \\
(0.028)\end{array}$ & $\begin{array}{c}0.59 \\
(0.024)\end{array}$ & $\begin{array}{c}0.21 \\
(0.020)\end{array}$ & $\begin{array}{c}0.38 \\
(0.015)\end{array}$ & -35.3 & -27.3 \\
\hline Spot Premium & $\begin{array}{c}0.95 \\
(0.017)\end{array}$ & $\begin{array}{c}0.95 \\
(0.017)\end{array}$ & $\begin{array}{c}0.90 \\
(0.020)\end{array}$ & $\begin{array}{c}0.91 \\
(0.015)\end{array}$ & -1.03 & -3.05 \\
\hline \multicolumn{7}{|c|}{ Canadian Dollar } \\
\hline Forward Rate & $\begin{array}{c}0.87 \\
(0.052)\end{array}$ & $\begin{array}{c}0.87 \\
(0.052)\end{array}$ & $\begin{array}{c}0.85 \\
(0.018)\end{array}$ & $\begin{array}{c}0.87 \\
(0.014)\end{array}$ & -0.30 & -0.94 \\
\hline Spot Rate & $\begin{array}{c}0.95 \\
(0.024)\end{array}$ & $\begin{array}{c}0.94 \\
(0.024)\end{array}$ & $\begin{array}{c}0.91 \\
(0.018)\end{array}$ & $\begin{array}{c}0.96 \\
(0.014)\end{array}$ & 0.19 & -0.30 \\
\hline Forward Premium & $\begin{array}{c}0.41 \\
(0.009)\end{array}$ & $\begin{array}{c}0.41 \\
(0.009)\end{array}$ & $\begin{array}{c}0.34 \\
(0.019)\end{array}$ & $\begin{array}{c}0.47 \\
(0.014)\end{array}$ & -42.9 & -24.7 \\
\hline Spot Premium & $\begin{array}{c}0.92 \\
(0.030)\end{array}$ & $\begin{array}{c}0.92 \\
(0.030)\end{array}$ & $\begin{array}{c}0.92 \\
(0.019)\end{array}$ & $\begin{array}{c}0.93 \\
(0.014)\end{array}$ & 1.33 & -3.69 \\
\hline \multicolumn{7}{|c|}{ JAPANESE YEN } \\
\hline Forward Rate & $\begin{array}{c}0.99 \\
(0.029)\end{array}$ & $\begin{array}{c}0.99 \\
(0.029)\end{array}$ & $\begin{array}{c}1.01 \\
(0.020)\end{array}$ & $\begin{array}{l}0.97 \\
(0.015)\end{array}$ & 0.16 & -0.95 \\
\hline Spot Rate & $\begin{array}{c}1.03 \\
(0.017)\end{array}$ & $\begin{array}{c}1.03 \\
(0.017)\end{array}$ & $\begin{array}{c}1.01 \\
(0.020)\end{array}$ & $\begin{array}{c}0.97 \\
(0.015)\end{array}$ & 0.12 & 0.96 \\
\hline Forward Premium & $\begin{array}{c}0.65 \\
(0.028)\end{array}$ & $\begin{array}{c}0.67 \\
(0.026)\end{array}$ & $\begin{array}{c}0.45 \\
(0.020)\end{array}$ & $\begin{array}{c}0.60 \\
(0.015)\end{array}$ & -35.0 & -22.3 \\
\hline Spot Premium & $\begin{array}{c}0.95 \\
(0.032)\end{array}$ & $\begin{array}{c}0.95 \\
(0.032)\end{array}$ & $\begin{array}{c}0.99 \\
(0.020)\end{array}$ & $\begin{array}{l}0.97 \\
(0.015)\end{array}$ & -3.42 & -4.23 \\
\hline
\end{tabular}

Note: standard errors in parentheses. 
Table 3: $I(1) / I(0)$ Levels Regression Analysis

\begin{tabular}{|c|c|c|c|c|c|c|}
\hline REGRESSIONS & $\alpha$ & $\beta$ & $R^{2}$ & $\mathrm{ADF}^{\dagger}$ & $\mathrm{NP}^{\dagger}$ & $\mathrm{KPSS}^{\dagger}$ \\
\hline \multicolumn{7}{|c|}{ AUStralian DOLlar } \\
\hline$s_{t}$ on $f_{t, k}$ & $\begin{array}{l}-0.002 \\
(0.0003)\end{array}$ & $\begin{array}{l}0.995 \\
(0.001)\end{array}$ & 0.998 & No & No & Yes \\
\hline$s_{t+k}$ on $f_{t, k}$ & $\begin{array}{l}0.1169 \\
(0.005)\end{array}$ & $\begin{array}{l}0.717 \\
(0.005)\end{array}$ & 0.63 & Yes & No & Yes \\
\hline$\Delta_{k} s_{t+k}$ on $\left\{f_{t, k}-s_{t}\right\}$ & $\begin{array}{l}-0.001 \\
(0.001)\end{array}$ & $\begin{array}{l}2.29 \\
(0.02)\end{array}$ & 0.03 & Yes & Yes & No \\
\hline \multicolumn{7}{|c|}{ Canadian Dollar } \\
\hline$s_{t}$ on $f_{t, k}$ & $\begin{array}{l}0.017 \\
(0.002)\end{array}$ & $\begin{array}{l}0.955 \\
(0.002)\end{array}$ & 0.93 & Yes & Yes & Yes \\
\hline$s_{t+k}$ on $f_{t, k}$ & $\begin{array}{c}0.109 \\
(0.005)\end{array}$ & $\begin{array}{l}0.700 \\
(0.013)\end{array}$ & 0.50 & Yes & Yes & No \\
\hline$\Delta_{k} s_{t+k}$ on $\left\{f_{t, k}-s_{t}\right\}$ & $\begin{array}{c}0.002 \\
(0.0004)\end{array}$ & $\begin{array}{l}-1.96 \\
(0.231)\end{array}$ & 0.026 & Yes & Yes & No \\
\hline \multicolumn{7}{|c|}{ JAPANESE YEN } \\
\hline$s_{t}$ on $f_{t, k}$ & $\begin{array}{l}-0.007 \\
(0.001)\end{array}$ & $\begin{array}{l}1.005 \\
(0.001)\end{array}$ & 0.999 & No & No & Yes \\
\hline$s_{t+k}$ on $f_{t, k}$ & $\begin{array}{l}0.386 \\
(0.025)\end{array}$ & $\begin{array}{l}0.832 \\
(0.025)\end{array}$ & 0.72 & Yes & No & No \\
\hline$\Delta_{k} s_{t+k}$ on $\left\{f_{t, k}-s_{t}\right\}$ & $\begin{array}{l}-0.008 \\
(0.003)\end{array}$ & $\begin{array}{l}-0.917 \\
(0.470)\end{array}$ & 0.002 & Yes & Yes & No \\
\hline
\end{tabular}

†Yes - significant at 5 per cent level. No - not significant at 5 per cent level. Note: standard errors in parentheses. 
Table 4: Fractional Integration Results for the Levels Regression Residuals

\begin{tabular}{|c|c|c|c|c|c|c|}
\hline REGRESSIONS & EML & NLS & GPH & GSP & FDF & FADF \\
\hline \multicolumn{7}{|c|}{ Australian Dollar } \\
\hline$s_{t}$ on $f_{t, k}$ & $\begin{array}{c}0.34 \\
(0.01)\end{array}$ & $\begin{array}{c}0.34 \\
(0.01)\end{array}$ & $\begin{array}{c}0.23 \\
(0.020)\end{array}$ & $\begin{array}{c}0.39 \\
(0.015)\end{array}$ & -38.56 & -25.70 \\
\hline$s_{t+k}$ on $f_{t, k}$ & $\begin{array}{l}0.97 \\
(0.02)\end{array}$ & $\begin{array}{l}0.97 \\
(0.02)\end{array}$ & $\begin{array}{c}0.89 \\
(0.020)\end{array}$ & $\begin{array}{c}0.91 \\
(0.015)\end{array}$ & -0.32 & -2.90 \\
\hline$\Delta_{k} s_{t+k}$ on $\left\{f_{t, k}-s_{t}\right\}$ & $\begin{array}{l}0.84 \\
(0.02)\end{array}$ & $\begin{array}{l}0.84 \\
(0.02)\end{array}$ & $\begin{array}{l}0.80 \\
(0.020)\end{array}$ & $\begin{array}{l}0.85 \\
(0.015)\end{array}$ & -6.17 & -5.23 \\
\hline \multicolumn{7}{|c|}{ CANadian Dollar } \\
\hline$s_{t}$ on $f_{t, k}$ & $\begin{array}{l}0.21 \\
(0.02)\end{array}$ & $\begin{array}{c}0.22 \\
(0.02)\end{array}$ & $\begin{array}{c}0.06 \\
(0.018)\end{array}$ & $\begin{array}{c}0.14 \\
(0.014)\end{array}$ & -48.57 & -34.57 \\
\hline$s_{t+k}$ on $f_{t, k}$ & $\begin{array}{l}0.85 \\
(0.03)\end{array}$ & $\begin{array}{l}0.85 \\
(0.03)\end{array}$ & $\begin{array}{c}0.60 \\
(0.017)\end{array}$ & $\begin{array}{c}0.67 \\
(0.014)\end{array}$ & -23.34 & -11.26 \\
\hline$\Delta_{k} s_{t+k}$ on $\left\{f_{t, k}-s_{t}\right\}$ & $\begin{array}{l}0.91 \\
(0.02)\end{array}$ & $\begin{array}{l}0.91 \\
(0.02)\end{array}$ & $\begin{array}{c}0.84 \\
(0.018)\end{array}$ & $\begin{array}{l}0.88 \\
(0.014)\end{array}$ & -5.62 & -3.64 \\
\hline \multicolumn{7}{|c|}{ JAPANESE YEN } \\
\hline$s_{t}$ on $f_{t, k}$ & $\begin{array}{l}0.47 \\
(0.16)\end{array}$ & $\begin{array}{l}0.50 \\
(0.14)\end{array}$ & $\begin{array}{c}0.33 \\
(0.021)\end{array}$ & $\begin{array}{c}0.43 \\
(0.015)\end{array}$ & -38.36 & -25.47 \\
\hline$s_{t+k}$ on $f_{t, k}$ & $\begin{array}{l}0.77 \\
(0.07)\end{array}$ & $\begin{array}{l}0.77 \\
(0.07)\end{array}$ & $\begin{array}{c}0.99 \\
(0.020)\end{array}$ & $\begin{array}{l}0.98 \\
(0.015)\end{array}$ & 2.45 & -2.53 \\
\hline$\Delta_{k} s_{t+k}$ on $\left\{f_{t, k}-s_{t}\right\}$ & $\begin{array}{l}0.95 \\
(0.03)\end{array}$ & $\begin{array}{l}0.95 \\
(0.03)\end{array}$ & $\begin{array}{c}0.99 \\
(0.020)\end{array}$ & $\begin{array}{l}0.98 \\
(0.015)\end{array}$ & 2.90 & -2.31 \\
\hline
\end{tabular}

Note: standard errors in parentheses. 
Table 5: Hamilton Estimates

\begin{tabular}{|c|c|c|c|c|c|}
\hline \multicolumn{3}{|c|}{ RATES } & \multicolumn{3}{|c|}{ Premiums } \\
\hline & \multicolumn{2}{|c|}{ Estimates } & & \multicolumn{2}{|c|}{ Estimates } \\
\hline$c$ & $\begin{array}{c}-0.001 \\
(0.002)\end{array}$ & & $c$ & $\begin{array}{c}2.741 \\
(6.090)\end{array}$ & \\
\hline$f_{t, k}$ & $\begin{array}{l}1.004 \\
(0.004)\end{array}$ & $\begin{array}{c}1.003 \\
(0.002)\end{array}$ & $f_{t, k}-s_{t}$ & $\begin{array}{l}1.305 \\
(0.578)\end{array}$ & $\begin{array}{c}1.267 \\
(0.580)\end{array}$ \\
\hline$t$ & $\begin{array}{c}0.0002 \\
(0.0003)\end{array}$ & $\begin{array}{c}0.0001 \\
(0.0002)\end{array}$ & $t$ & $\begin{array}{l}-0.246 \\
(2.144)\end{array}$ & $\begin{array}{c}0.503 \\
(0.727)\end{array}$ \\
\hline Nonlinear & & & Nonlinear & & \\
\hline$\sigma$ & $\begin{array}{c}0.001 \\
(0.00002)\end{array}$ & $\begin{array}{c}0.001 \\
(0.00002)\end{array}$ & $\sigma$ & $\begin{array}{l}0.128 \\
(0.967)\end{array}$ & $\begin{array}{c}0.060 \\
(0.538)\end{array}$ \\
\hline$\zeta$ & $\begin{array}{l}1.974 \\
(0.245)\end{array}$ & $\begin{array}{l}-1.629 \\
(0.192)\end{array}$ & $\zeta$ & $\begin{array}{c}84.867 \\
(639.699)\end{array}$ & $\begin{array}{c}182.803 \\
(1649.346)\end{array}$ \\
\hline$f_{t, k}$ & $\begin{array}{c}-0.0001 \\
(0.064)\end{array}$ & $\begin{array}{c}-0.0002 \\
(0.064)\end{array}$ & $f_{t, k}-s_{t}$ & $\begin{array}{l}-0.014 \\
(0.036)\end{array}$ & $\begin{array}{c}-0.015 \\
(0.034)\end{array}$ \\
\hline$t$ & $\begin{array}{c}1.169 \\
(0.102)\end{array}$ & $\begin{array}{l}1.866 \\
(0.152)\end{array}$ & $t$ & $\begin{array}{c}-12.893 \\
(0.599)\end{array}$ & $\begin{array}{l}12.888 \\
(0.598)\end{array}$ \\
\hline
\end{tabular}

Note 1: coefficient estimates for $f_{t, k}$, allow for rescaling; see Section 7. Note 2: standard errors in parentheses. 


\section{A.2 Figures}



Figure 1: Rate regression with trend

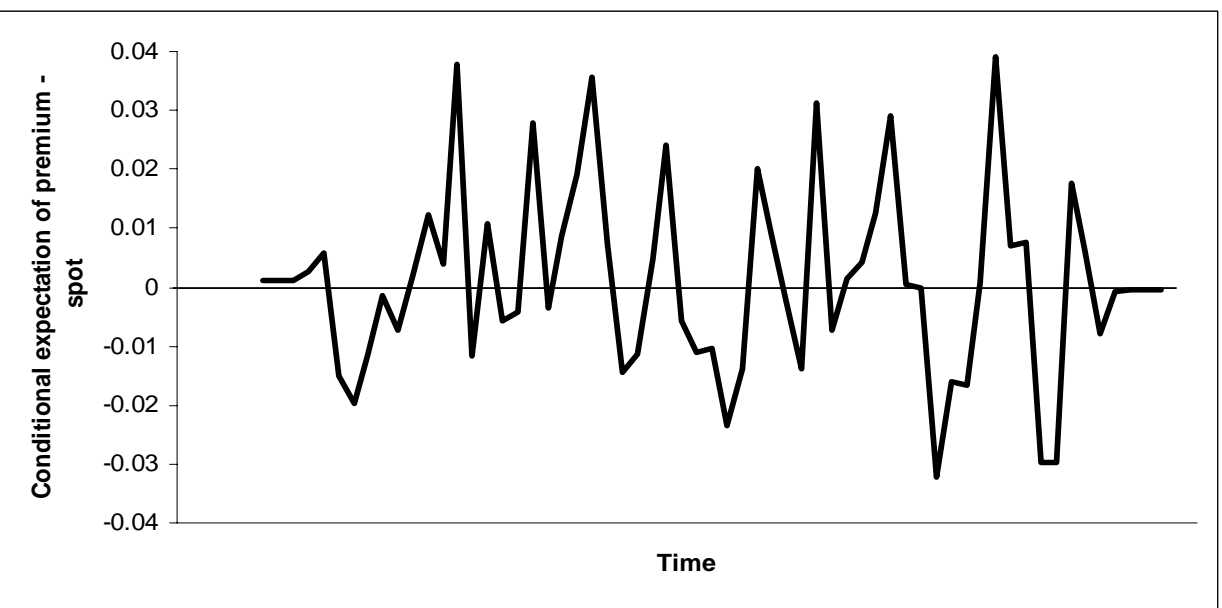

Figure 2: Premium regression with trend 